\title{
Investigating the dynamics of bulk snow density in dry and wet conditions using a one-dimensional model
}

\author{
C. De Michele ${ }^{1}$, F. Avanzi ${ }^{1}$, A. Ghezzi ${ }^{1}$, and C. Jommi ${ }^{1,2}$ \\ ${ }^{1}$ Department of Civil and Environmental Engineering - Politecnico di Milano, Milano, Italy \\ ${ }^{2}$ Department of Geoscience and Engineering - Delft University of Technology, Delft, the Netherlands
}

Correspondence to: C. De Michele (carlo.demichele@polimi.it)

Received: 6 June 2012 - Published in The Cryosphere Discuss.: 4 July 2012

Revised: 5 December 2012 - Accepted: 13 February 2013 - Published: 7 March 2013

\begin{abstract}
The snowpack is a complicated multiphase mixture with mechanical, hydraulic, and thermal properties highly variable during the year in response to climatic forcings. Bulk density is a macroscopic property of the snowpack used, together with snow depth, to quantify the water stored. In seasonal snowpacks, the bulk density is characterized by a strongly non-linear behaviour due to the occurrence of both dry and wet conditions. In the literature, bulk snow density estimates are obtained principally with multiple regressions, and snowpack models have put the attention principally on the snow depth and snow water equivalent. Here a one-dimensional model for the temporal dynamics of the snowpack, with particular attention to the bulk snow density, has been proposed, accounting for both dry and wet conditions. The model represents the snowpack as a twoconstituent mixture: a dry part including ice structure, and air; and a wet part constituted by liquid water. It describes the dynamics of three variables: the depth and density of the dry part and the depth of liquid water. The model has been calibrated and validated against hourly data registered at three SNOTEL stations, western US, with mean values of the Nash-Sutcliffe coefficient $\approx 0.73-0.97$ in the validation period.
\end{abstract}

\section{Introduction}

Snowpacks and glaciers provide water supply to more than a sixth of the global population (Barnett et al., 2005). In the western United States, the snowpack is the principal source of water supply, since about $50-70 \%$ of the annual precipitation in the mountainous regions falls as snow and is stored in the snowpack. Snowpacks dynamics are strongly dependent on temperature variability. Hydro-climatological data, relative to the period 1950-1999, indicate a decline of snowpack in much of the western United States (Pierce et al., 2008). Recent studies suggest that future scenarios of warming temperature will inevitably alter the distribution and magnitude of snowpack in many areas (Barnett et al., 2005).

As a consequence of all these elements, modeling the snowpack mass dynamics is of preeminent importance in managing present resources exploitation, and one of the most important scientific topics for future scenarios of resource availability in cold regions.

The snowpack is a multiphase mixture of three constituents - ice, liquid water, and air - subject to climatic forcings. The ice crystals are organized in cellular structures, or porous matrices, which are the skeleton of the snowpack, and principal responsible for its mechanical properties. Liquid water, produced by melting and rainfall phenomena, occupies the available spaces within the snowpack and modifies the properties of the solid structure (DeWalle and Rango, 2008). Snowpacks are characterized by a continuous alternation of dry and wet conditions, especially during the melting season, due to thermal phase transitions. These changes of phase complicate the theoretical description and the practical reconstruction of the mass dynamics.

In the literature, models representing the dynamics of snowpack can be categorized according to the type of energetic description (Hock, 2003). Some snowpack models (e.g. Anderson, 1976; Kondo and Yamazaki, 1990; Bartelt and Lehning, 2002; Ohara and Kavvas, 2006) implement an explicit energetic balance to predict snow temperature and melting, whereas other models use the air temperature as the 
sole index to describe the heat exchange between the snowpack and the atmosphere, calibrating to this aim site-specific parameters (see e.g. Ohmura, 2001). The former models provide a detailed description of the snow accumulation and ablation dynamics, but they are characterized by a heavy parametrization and require a number of input data. The latter ones are surely simpler but also provide an approximated description of the phenomena, requiring usually less input data. However, a re-calibration of the parameters is needed when transferring the model to other areas. This fact represents the main limitation of this approach (Bales et al., 2006).

Snowpack models can be also distinguished, according to the number of layers considered (Vionnet et al., 2012), into: (1) single-layer models (see e.g. Tarboton and Luce, 1996; Jansson and Karlberg, 2004; Ohara and Kavvas, 2006), (2) two-layer models (Marks et al., 1998; Koivusalo et al., 2001), and (3) multi-layer models (see e.g. Anderson, 1976; Jordan, 1991; Bartelt and Lehning, 2002; Zhang et al., 2008; Rutter et al., 2008; Kelleners et al., 2009). The choice of a singlelayer, rather than a multi-layer, model is dependent on the specific problem one wants to address. For the modeling of avalanches, it is important a detailed description of the snowpack, layer by layer, and thus a multi-layer model is to be preferred. On the other hand, for the evaluation of the water stored within the snowpack, a global description can be sufficient and consequently a single-layer, or a two-layer, model can be satisfactory for this purpose.

To assist decision makers in water resources management and forecasting, a reliable description of snowpack mass dynamics is needed. As seen, this request can be addressed with different models of various complexity. Typical input data for a complex snowpack model are precipitation, air temperature, radiation, wind speed and humidity (Anderson, 1976; Lehning et al., 2002). These data are usually derived from manual measures or automatic weather stations (Lehning et al., 2002; Fierz et al., 2009). However, the spatial frequency of gauging stations is dependent on the area of interest. This fact limits the exploiting of complex snowpack dynamics models to limited areas. Therefore, simple models, with less input requirements, are highly desiderable. To this purpose, the direct characterization of SWE dynamics for regional hydroloy applications is rather difficult, especially at catchment scale (Bavera and De Michele, 2009), since SWE experimental data are usually scarcer than, for example, snow depth data (Mizukami and Perica, 2008).

An alternative solution is to estimate the bulk snow density which, together with snow depth, returns an estimation of SWE. However, the temporal dynamics of bulk snow density are characterized by a highly non-linear behaviour, especially at the beginning of the accumulation season, and at end of the melting season (Mizukami and Perica, 2008), depending on the status of the snowpack, dry or wet. The former status occurs principally during the accumulation season, while the latter one during the melting season. Estimates of the bulk density of the snowpack are often operated via multiple regressions on variables including snow depth, temperature, site altitude, wind velocity (Meløysund et al., 2007; Bavera and De Michele, 2009; Jonas et al., 2009; Bavera et al., 2012), with values of the determination coefficient up to $\approx 0.70$.

In addition, the modeling efforts have been concentrated principally on dry snowpacks rather than on wet snowpacks, as pointed out by Bartelt and Lehning (2002). An example of some simple approaches is reported in Essery et al. (1999).

Therefore, the main purpose of this contribution is to present the formulation of a simple point model which represents the dynamics of bulk snow density, snow depth and, as a derived value, SWE. It is based on hourly input data of precipitation and air temperature. To model the snowpack evolution during its presence on the ground, liquid and solid water contents of the snowpack have to be predicted separately (Kerkez et al., 2010). To this purpose, we introduce a simple one-dimensional model where the snowpack is represented as a two-constituent mixture: a dry part including the ice structure, and air; and a wet part constituted by liquid water. The model includes mass balance equations of dry and wet constituents, momentum balance and rheological equations for the dry part, and a simplified energetic description of the snowpack. It results in a system of three differential equations in the state variables: the depth and the density of the dry part, and the depth of liquid water. With respect to the existing literature, the model can be assimilated to a singlelayer approach when the snowpack is dry, and to a two-layer model when the snowpack is wet, with a saturated layer at the bottom as in the representation of Colbeck (1974). Since late 1990, the SNOTEL (SNOwpack TELemetry) network in the western US has carried out systematic measurements of bulk snow density using the snow pillow technology. Data are available at the daily and hourly time scales. We test the performances of the model against the data of three SNOTEL stations in both the calibration and validation phases.

The model can be adopted to predict SWE availability at the point scale, or to check the quality of automatic weather stations data (i.e. snow depth, snow density and SWE). The results show how the model is able to predict the mean volumetric liquid water content of a snowpack without having direct experimental measurements or using complex model formulations. Additionally, the simulated variables are of interest also for remote sensing validation (Dietz et al., 2011). The physical formulation of the model, combined to the fair input data required, make the model easily applicable to other sites even ungauged, overcoming the paucity of SWE data.

\section{Methods}

\subsection{Definitions}

During the accumulation period, liquid water is scarce, and the snowpack is usually referred to as dry. Conversely, during 

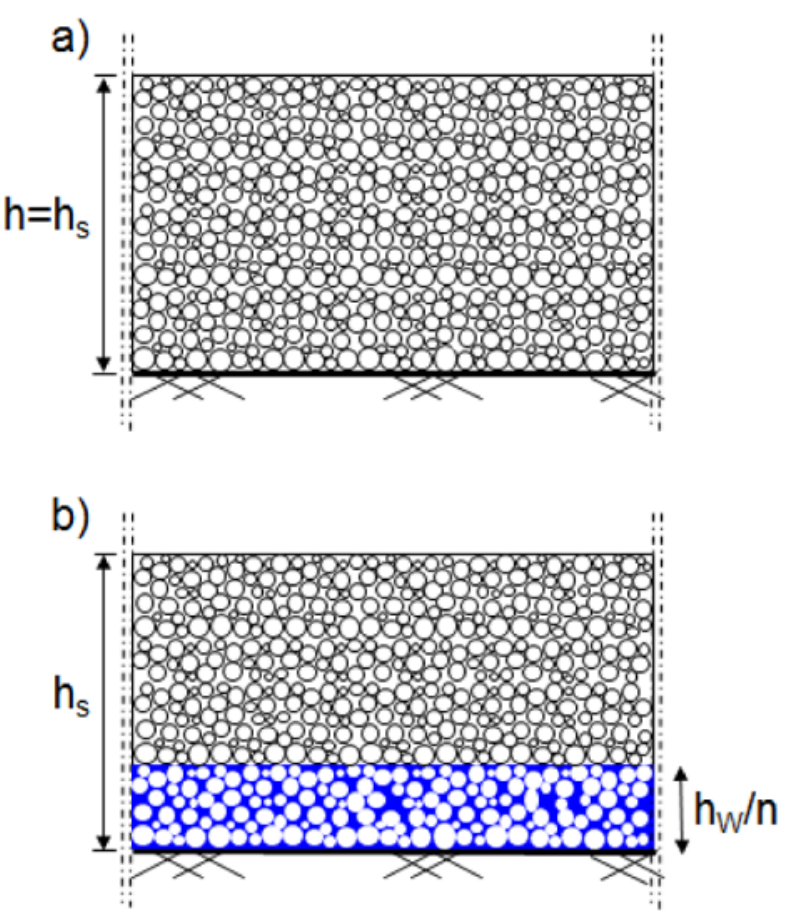

Fig. 1. Snowpack in dry condition (a), and in wet condition (b).

the melting season, liquid water is present and the snowpack is referred to as wet (Fierz et al., 2009). Considering the snowpack to be composed by two constituents only, a dry part including ice structure and air, and a wet part including liquid water, we will be able to follow the dynamics of snowpacks in wet and dry conditions.

Let us consider a control volume of snowpack $V$, of unitary area and height $h$. Let $V_{\mathrm{S}}$ be the volume occupied by the porous matrix of height $h_{\mathrm{S}}, V_{\mathrm{W}}$ the volume of liquid water of height $h_{\mathrm{W}}$, and $V_{\mathrm{P}}$ the volume of pores within the ice matrix. Let $n=V_{\mathrm{P}} / V_{\mathrm{S}}$ indicate the porosity, and $\phi=V_{\mathrm{W}} / V_{\mathrm{P}}$ the degree of saturation of the ice matrix. The distinction between $V_{\mathrm{S}}$ and $V$ is necessary to correctly represent the last instants of the melting phase before the complete disappearance of the snowpack. In normal conditions, i.e. dry, sub-saturated, and saturated, we have that $V=V_{\mathrm{S}}$. Figure 1 reports a sketch of the snowpack in dry (1a) and wet condition (1b). During the last hours of the snowpack existence, the dry part leaves space to the liquid part, which becomes predominant, with $V>V_{\mathrm{S}}$. Then, from a general point of view, the control volume can be expressed as $V=V_{\mathrm{S}}+<V_{\mathrm{W}}-n V_{\mathrm{S}}>$, and similarly can be done for the height $h=h_{\mathrm{S}}+<h_{\mathrm{W}}-n h_{\mathrm{S}}>$, where $<$ and $>$ are Macaulay brackets, providing the argument if this is positive, otherwise 0 .

Let $\theta=V_{\mathrm{W}} / V$ indicate the volumetric liquid water content. Let $M_{\mathrm{D}}$ be the dry mass of the snowpack, including ice and air, and $M_{\mathrm{W}}$ the liquid water mass. Clearly the mass of snowpack is $M=M_{\mathrm{D}}+M_{\mathrm{W}}$. Let us indicate the bulk density of dry mass with $\rho_{\mathrm{D}}=M_{\mathrm{D}} / V_{\mathrm{S}}$, the density of water with $\rho_{\mathrm{W}}=M_{\mathrm{W}} / V_{\mathrm{W}}=1000\left(\mathrm{~kg} \mathrm{~m}^{-3}\right)$, and the bulk density of snowpack with $\rho=M / V$. Consequently, $\rho$ can be calculated as $\rho=\left(\rho_{\mathrm{D}} h_{\mathrm{S}}+\rho_{\mathrm{W}} h_{\mathrm{W}}\right) / h$. As range of variability, $\rho_{\mathrm{F}} \leq \rho_{\mathrm{D}} \leq \rho_{\mathrm{ICE}}=917\left(\mathrm{~kg} \mathrm{~m}^{-3}\right)$, and $\rho_{\mathrm{F}} \leq \rho \leq \rho_{\mathrm{W}}$ $\left(\mathrm{kg} \mathrm{m}^{-3}\right)$, where $\rho_{\mathrm{F}}$ is the density of the fresh snow (generally between $50 \mathrm{~kg} \mathrm{~m}^{-3}$ and $200 \mathrm{~kg} \mathrm{~m}^{-3}$ ). Accordingly, the porosity will be calculated as $n=\left(1-\rho_{\mathrm{D}} / \rho_{\mathrm{ICE}}\right)$.

\subsection{Equations of the snowpack}

The dynamics of the snowpack are described through a set of mass balance, momentum, energy and rheological equations. The equations are described in the integral form. We simplify the energetic description of the snowpack as follows: (1) we assume that the constituents are in thermal equilibrium so that it is necessary to use only one energy balance equation. (2) Following Kondo and Yamazaki (1990), we consider a bilinear behaviour of the temperature $T(z)$ through the depth $z \in\left(0, h_{\mathrm{S}}\right)$ of the snowpack (depth unit is fixed in meters henceforth). If the air temperature $T_{\mathrm{A}}<0{ }^{\circ} \mathrm{C}$, then $T(z)=T_{\mathrm{A}}-a_{T}\left(z-h_{\mathrm{S}}\right)$ for $h_{\mathrm{S}} \geq z \geq z_{0}$, and $T(z)=$ $0^{\circ} \mathrm{C}$, for $z_{0} \geq z \geq 0$, where $a_{T} \approx 0.033\left({ }^{\circ} \mathrm{C} \mathrm{mm}^{-1}\right)$, and $z_{0}$ is the maximum value of $z$ characterized by a temperature equal to $0^{\circ} \mathrm{C}$. Conversely, if $T_{\mathrm{A}} \geq 0{ }^{\circ} \mathrm{C}$, then $T(z)=0^{\circ} \mathrm{C}$, $\forall z$. Thus, the depth-averaged temperature of the snowpack is $T_{\mathrm{S}}=\frac{1}{h_{\mathrm{S}}} \int_{0}^{h_{\mathrm{S}}} T(z) \mathrm{d} z$. In this way, we use the air temperature as the sole index to describe the heat exchange between the snowpack and the atmosphere (Anderson, 1976; Ohmura, 2001). It is important to highlight that this approach fixes the temperature at the lower boundary of the snowpack equal to $0{ }^{\circ} \mathrm{C}$. This is supported by experimental evidence given by Ohara and Kavvas (2006) and Zhang et al. (2008), confirming that the lower part of the snowpack can be modeled as a thermal inactive boundary. No thermal exchange with the ground is therefore considered. This assumption could not be valid in Arctic or alpine tundra environments, as described by Zhang (2005). The generalization of this approach in such environments is an important topic for future studies.

\subsubsection{Mass balance equations of the snowpack}

The mass balance equations in the integral form, with respect to $V$, for $M_{\mathrm{D}}$ and $M_{\mathrm{W}}$ are as follows:

$$
\begin{aligned}
\frac{\mathrm{d} M_{\mathrm{D}}}{\mathrm{d} t} & =\mathcal{P}_{\mathrm{S}}+\mathcal{F}-\mathcal{M}-\mathcal{S} \\
\frac{\mathrm{d} M_{\mathrm{W}}}{\mathrm{d} t} & =\mathcal{P}_{\mathrm{R}}-\mathcal{F}+\mathcal{M}-\mathcal{O}-\mathcal{E} .
\end{aligned}
$$

In Eq. (1), $\mathcal{P}_{\mathrm{S}}$ is the incoming mass flux due to snow events; $\mathcal{F}, \mathcal{M}$ and $\mathcal{S}$ are mass fluxes due to changing phase phenomena, respectively refreezing, melting, and sublimation; while $t$ is time in hours. $\mathcal{F}$ and $\mathcal{M}$ are the exchanging terms between $M_{\mathrm{D}}$ and $M_{\mathrm{W}}$. All fluxes are measured in $\left(\mathrm{kg} \mathrm{m}^{-2} \mathrm{~h}^{-1}\right)$. No mass flux of snow due to wind is considered in the model. 
In Eq. (2), $\mathcal{P}_{\mathrm{R}}$ is the incoming mass flux due to rain events, $\mathcal{O}$ and $\mathcal{E}$ are the outcoming mass fluxes, respectively, due to water outflow and evaporation phenomena. We will consider the case of a snowpack overlying an impermeable boundary, horizontal or with a small slope. This is because it represents the condition investigated in the case study: the snowpack dynamics over a snow-pillow. Consequently, as water outflow we will consider only the water movement in the horizontal direction, or parallel to the impermeable boundary (slope flow). We will assume also that the liquid water is accumulated in the lower part of the snowpack. The snowpack is then characterized by two layers, a saturated one and a dry one, as indicated in Fig. 1b. The water percolation from the top to the bottom of the snowpack is not modeled, since it is an internal flux with no effect on the integral mass balance. In addition, as a first approximation, we will neglect the refreezing, sublimation and evaporation terms.

The snow precipitation term can be written as $\mathcal{P}_{\mathrm{S}}=\rho_{\mathcal{F}} S$ where $s$ is the snow precipitation rate, generally expressed in $\left(\mathrm{m} \mathrm{h}^{-1}\right)$. Following Anderson (1976), $\rho_{\mathcal{F}}$ will be considered a function of the air temperature only, $T_{\mathrm{A}}$, at the beginning of the snow event, $\rho \mathcal{F}=50+1.7\left(T_{\mathrm{A}}+15\right)^{1.5}$ $\left(\mathrm{kg} \mathrm{m}^{-3}\right)$, if $-15^{\circ} \mathrm{C} \leq T_{\mathrm{A}} \leq 2{ }^{\circ} \mathrm{C}$, and $\rho \mathcal{F}=50\left(\mathrm{~kg} \mathrm{~m}^{-3}\right)$ if $T_{\mathrm{A}}<-15^{\circ} \mathrm{C}$. The term of liquid precipitation is written as $\mathcal{P}_{\mathrm{R}}=\rho_{\mathrm{W}} p$ where $p$ is the rain rate, expressed in $\left(\mathrm{m} \mathrm{h}^{-1}\right)$.

The melting term can be expressed, following a temperature-index approach (Ohmura, 2001), as $\mathcal{M}=$ $\rho_{\mathrm{D}} I\left(T_{\mathrm{A}}, M_{\mathrm{D}}\right)\left[a+b\left(T_{\mathrm{A}}-T_{\tau}\right)\right]$, where $I(-)$ is the product of a binary function equal to 1 if $\left\{T_{\mathrm{A}} \geq T_{\tau}\right\}$ and of a function of $M_{\mathrm{D}}$ which tends to 0 with $M_{\mathrm{D}} \cdot a\left(\mathrm{~m} \mathrm{~h}^{-1}\right)$ and $b\left(\mathrm{~m} \mathrm{~h}^{-1}{ }^{\circ} \mathrm{C}^{-1}\right)$ are two parameters, and $T_{\tau}$ is a temperature threshold. $T_{\tau}$ is usually assumed equal to $0^{\circ} \mathrm{C}$. The snowpack dynamics could be better represented by adopting different thresholds to reproduce the thermal inertia of the snowpack, which is usually defined as cold content (e.g. van den Broeke et al., 2010 or DeWalle and Rango, 2008). Nonetheless, as a first approximation, we assume $T_{\tau}=0^{\circ} \mathrm{C}$. Physically, $a$ is the melting coefficient at $T_{\mathrm{A}}=T_{\tau}$, while $b$ represents the increase of ablation with the temperature. The parameter $b$ is also known as a degree-hour factor. The temperature-index approach has been widely applied in the literature. Examples include Anderson (1976) and Hock (1999). Many literature reviews demonstrate that degree-day methods work well over long time periods, Hock (2003).

The water outflow, $\mathcal{O}$, depends on the hydraulic properties of the snowpack, which change significantly during the melting season (DeWalle and Rango, 2008). When water moves through the melting snowpack, many observations have shown the existence of preferential flow channels in horizontal and vertical directions (Gerdel, 1954; Marsh and Woo, 1984; Schneebeli, 1995). Thus, the hydraulic motion of water through the snowpack is both a "matrix flow" and a "preferential flow" (Waldner et al., 2004) in proportions that depend on the liquid water content. However, since this is still an open issue, here, as a first representation of the phenomenon, we model the water outflow through a kinematic wave approximation following Nomura (1994) and Singh (2001). In particular we assume that $\mathcal{O}=c \rho_{\mathrm{W}} \theta h_{\mathrm{W}}^{d}$ for $\theta>\theta_{\mathrm{r}}$, otherwise 0 , where $c\left(\mathrm{~m}^{-1} \mathrm{~h}^{-(d-1)}\right)$ and $d$ are two constants, and $\theta_{r}$ is the residual water content (value under which the residual amount of liquid water is retained into the ice matrix and only vapour exchanges occur). The residual water content is calculated as $\theta_{\mathrm{r}}=F_{\mathrm{C}} \rho_{\mathrm{D}} / \rho_{\mathrm{W}}$ where $F_{\mathrm{C}}$ is the mass of water that can be retained per mass of dry snow, assumed equal to 0.02, according to Tarboton and Luce (1996) and Kelleners et al. (2009). The coefficient $c$ is a site-specific parameter depending on factors like slope and altitude of the site. For the exponent $d$, Nomura (1994) proposed $d=1.25$, a value that we will use henceforth. Since $M_{\mathrm{D}}=\rho_{\mathrm{D}} h_{\mathrm{S}}$ and $M_{\mathrm{W}}=\rho_{\mathrm{W}} h_{\mathrm{W}}$, after some algebra, Eqs. (1-2) can be written as follows:

$$
\begin{aligned}
& \frac{\mathrm{d} h_{\mathrm{S}}}{\mathrm{d} t}=-\frac{h_{\mathrm{S}}}{\rho_{\mathrm{D}}} \frac{\mathrm{d} \rho_{\mathrm{D}}}{\mathrm{d} t}+\frac{\rho_{\mathrm{F}}}{\rho_{\mathrm{D}}} s-I\left(T_{\mathrm{A}}, h_{\mathrm{S}}\right)\left(a+b\left(T_{\mathrm{A}}-T_{\tau}\right)\right) \\
& \frac{\mathrm{d} h_{\mathrm{W}}}{\mathrm{d} t}=p+\frac{\rho_{\mathrm{D}}}{\rho_{\mathrm{W}}} I\left(T_{\mathrm{A}}, h_{\mathrm{S}}\right)\left(a+b\left(T_{\mathrm{A}}-T_{\tau}\right)\right)-c \theta h_{\mathrm{W}}^{d} .
\end{aligned}
$$

$I\left(T_{\mathrm{A}}, h_{\mathrm{S}}\right)$ is the product of a binary function equal to 1 if $\left\{T_{A} \geq T_{\tau}\right\}$ and of a function of $h_{\mathrm{S}}$ which tends to 0 with $h_{\mathrm{S}}$, $\frac{h_{\mathrm{S}}}{h_{\mathrm{S}}+k}$.

\subsubsection{Momentum balance and rheological equations of the snowpack}

The momentum balance equation in the integral form, for the dry phase of height $h_{\mathrm{S}}$, is as follows:

$\sigma-\rho_{\mathrm{D}} g h_{\mathrm{S}}=0$

where $\sigma$ is the vertical stress at the bottom of the ice matrix, and $g$ is the gravitational acceleration. Equation (5) is obtained assuming quasi-static conditions of the snowpack. Maxwell's law is assumed to describe the rheological equation linking the vertical stress $\sigma$ to the vertical viscous strain rate $\dot{\epsilon}, \eta=\frac{\sigma}{\dot{\epsilon}}$, where $\eta$ is the coefficient of viscosity (Mellor, 1975). The vertical deformation rate can be expressed as a function of the density of ice matrix (Kojima, 1967), i.e. $\dot{\epsilon}=\frac{1}{\rho_{\mathrm{D}}} \frac{\mathrm{d} \rho_{\mathrm{D}}}{\mathrm{d} t}$. Substituting these last equations in Eq. (5), we obtain the following:

$\left.\frac{\mathrm{d} \rho_{\mathrm{D}}}{\mathrm{d} t}\right|_{\mathrm{comp}}=\frac{\rho_{\mathrm{D}}^{2} g h_{\mathrm{S}}}{\eta}$.

Equation (6) models the dynamics of the bulk density of a dry constituent due to compaction, neglecting the contribution of metamorphisms, whose effects are hardly traceable using a one (or two)-layer approach. The coefficient $\eta$ is the product of two components: one due to compaction effect, $\eta_{\mathrm{C}}$, and the other to temperature change, $\eta_{T}$. Following Kojima (1967), $\eta_{\mathrm{C}}$ can be expressed as an exponential function of the snow density, i.e. $\eta_{\mathrm{C}} \propto e^{k_{0} \rho_{\mathrm{D}}}$ where $k_{0}$ is a 
constant. Similarly, following Mellor (1975), $\eta_{T}$ can be expressed as $\eta_{T} \propto e^{\left[k_{1}\left(T_{\tau}-T_{\mathrm{S}}\right)\right]}$, where $k_{1}$ is a constant, and $T_{\mathrm{S}}$ $\left({ }^{\circ} \mathrm{C}\right)$ is the temperature of the snowpack, derived using the simple description cited before. Consequently, Eq. (6) can be written, after Kongoli and Bland (2000), Ohara and Kavvas (2006) and Zhang et al. (2008), as follows:

$$
\left.\frac{\mathrm{d} \rho_{\mathrm{D}}}{\mathrm{d} t}\right|_{\text {comp }}=c_{1} \rho_{\mathrm{D}}^{2} h_{\mathrm{S}} e^{\left(0.08\left(T_{\mathrm{S}}-T_{\tau}\right)-0.021 \rho_{\mathrm{D}}\right)}
$$

where $c_{1}=0.001\left(\mathrm{~m}^{2} \mathrm{~h}^{-1} \mathrm{~kg}^{-1}\right)$. Equation (7) represents the time evolution of $\rho_{\mathrm{D}}$ as consequence of compaction. This approach neglects the effect of interstitial liquid water on compaction, although many literature contributions show that snow constitutive behaviour changes with increasing the liquid content (see, e.g. Marshall et al., 1999; Izumi and Akitaya, 1985). Nonetheless, the snow pillow data do not allow for distinguishing between the effects of pore saturation and compaction on $\rho$.

The temporal derivative of $\rho_{\mathrm{D}}$ can be written as follows:

$\frac{\mathrm{d} \rho_{\mathrm{D}}}{\mathrm{d} t}=\frac{\mathrm{d}\left(M_{\mathrm{D}} / V_{\mathrm{S}}\right)}{\mathrm{d} t}=\frac{1}{V_{\mathrm{S}}} \frac{\mathrm{d} M_{\mathrm{D}}}{\mathrm{d} t}-\frac{M_{\mathrm{D}}}{V_{\mathrm{S}}^{2}} \frac{\mathrm{d} V_{\mathrm{S}}}{\mathrm{d} t}$.

From Eq. (8), it is possible to see how the temporal variability of $\rho_{\mathrm{D}}$ is the sum of two terms: the first one depending on the dry mass variation, and the second one on the dry volume variation. If $\frac{\mathrm{d} M_{\mathrm{D}}}{\mathrm{d} t}=0$, then $\frac{\mathrm{d} \rho_{\mathrm{D}}}{\mathrm{d} t}=-\frac{M_{\mathrm{D}}}{V_{\mathrm{S}}^{2}} \frac{\mathrm{d} V_{\mathrm{S}}}{\mathrm{d} t}$ and the variation of $\rho_{\mathrm{D}}$ is due only to the variation of the volume of the dry constituent, as it happens in compaction when no snow events occur. Equation (8) includes as a particular case Eq. (7). Snow events entail variations of both mass and volume of the dry constituent. From Eq. (8), it is possible to show that the temporal variability of $\rho_{\mathrm{D}}$ due to a snow event is $\frac{\mathrm{d} \rho_{\mathrm{D}}}{\mathrm{d} t}=\frac{\rho_{F}}{h_{\mathrm{S}}} s-\frac{\rho_{\mathrm{D}}}{h_{\mathrm{S}}} s$. A similar result is also reported in Ohara and Kavvas (2006). Here we assume that melting phenomena occur at $\rho_{\mathrm{D}}=$ const, i.e. mass variations balance volume variations. Consequently, Eq. (8) can be written as follows:

$\frac{\mathrm{d} \rho_{\mathrm{D}}}{\mathrm{d} t}=c_{1} h_{\mathrm{S}} \rho_{\mathrm{D}}^{2} e^{\left(0.08\left(T_{\mathrm{S}}-T_{\tau}\right)-0.021 \rho_{\mathrm{D}}\right)}+\frac{\left(\rho_{F}-\rho_{\mathrm{D}}\right)}{h_{\mathrm{S}}} s$.

Equations (3), (4), (9) represent a system of three differential equations in the three state variables $h_{\mathrm{S}}, h_{\mathrm{W}}$, and $\rho_{\mathrm{D}}$, forced by the meteorological variables $\left(p, s, T_{\mathrm{A}}\right)$ and with a parsimonious parametrization: three parameters have to be calibrated, $a, b$, and $c$. The other parameters $\left(c_{1}, d, T_{\tau}, F_{\mathrm{C}}\right)$ are fixed. Once solving the system of Eqs. (3), (4), and (9), we can obtain the dynamics of the other variables of interest and in particular the bulk density of the snowpack $\rho$.

\subsection{Numerical integration}

The system of Eqs. (3), (4), and (9) has been solved numerically using the forward Euler finite-difference scheme. A fixed time step, $\Delta t$, of one hour (congruent with the data series resolution) has been used. The modeled values of the state variables at the time instant $t+1$ have been calculated using values at the previous time step $t$, and considering that the time derivatives are calculated as $(f(t+1)-f(t)) / \Delta t$, where $f=h_{\mathrm{S}}, h_{\mathrm{W}}, \rho_{\mathrm{D}}$. As initial values, we set the state variables $h_{\mathrm{S}}$ and $h_{\mathrm{W}}$ at zero, if at the beginning of the first water year no snowpack is present, as in the case of seasonal snowpacks, and the calculation of dry density has been conditioned to the existence of snowpack, i.e. $h_{\mathrm{S}}>0$. Equation (9) is not defined for $h_{\mathrm{S}}=0$, as already pointed out by Ohara and Kavvas (2006). To avoid this inconvenience, the second term of Eq. (9) is calculated as $\frac{\left(\rho_{F}(t)-\rho_{\mathrm{D}}(t)\right)}{h_{\mathrm{S}}(t)+s(t) \Delta t} s(t)$. Note that, in this way, on the one hand it is possible to evaluate the new snow event effect on the density dynamics with an updated snow depth, and on the other hand it is possible to keep the benefits of an explicit finite-difference scheme. Clearly an implicit scheme could provide a more accurate evaluation of the dynamics, but with longer computation times. Thus, we obtain simulated time series of the variables $h_{\mathrm{S}}, h_{\mathrm{W}}$, and $\rho_{\mathrm{D}}$. From this we calculate time series of $h, \rho$, and SWE, which can be compared with observed data.

\section{Data and Results}

\subsection{SNOTEL network}

SNOTEL (SNOwpack TELemetry) is a network of roughly 750 automatic snow stations which covers 13 states of the western United States, from Alaska to the southern states of California, Arizona and New Mexico. This network has been installed and maintained by the Natural Resources Conservation Service (NRCS) since the beginning of the twentieth century. We have decided to test the model against SNOTEL data because of the abundant information available and the wide distribution of stations and data series. All the information used here have been verified at http: //www.wcc.nrcs.usda.gov/snow/ and by contacting directly SNOTEL staff. Each station provides measurements of snow water equivalent, snow depth, air temperature and total precipitation. Additionally, many other variables of interest are sometimes collected, such as air humidity and pressure, soil temperature, wind direction and velocity. Unfortunately no measurement of liquid water content is available at the SNOTEL gauges.

Each site of SNOTEL network is equipped with a snow pillow for the measurement of SWE and an ultrasonic device for snow depth. The air temperature is measured by a thermistor, while the total precipitation is held inside an automatic precipitation gauge. The snow depth sensor is also furnished with an additional temperature probe, which measures air temperature and therefore adjusts the measured distance of the target by compensating the variation of the speed of sound caused by temperature variations. The data resolution is of 0.1 inch (i.e. $2.45 \mathrm{~mm}$ ) for SWE and precipitation 
data, 1 inch (i.e. $2.45 \mathrm{~cm}$ ) for snow depth, and $0.1^{\circ} \mathrm{C}$ for air temperature. Daily data of SWE and precipitation systematically receive quality checks by SNOTEL technicians, and many works have demonstrated the good quality of these data (see, e.g. Serreze et al., 1999). On the other hand, hourly data are not subjected to any systematic quality check (SNOTEL staff, personal communications, 2011). Consequently, errors may affect the latter type of data series: they include missing data, fluctuations due to temperature effects (both for pressure transducer based measurements and for snow depth data), or errors due to instrumentation leaks, which have limited their use in the past. However, since the hourly resolution is more adequate than the daily one to represent the temporal variability of snowpack processes and forcings, we will consider hourly data.

\subsection{Case study}

As case study we have considered three weather stations of the SNOTEL network: (S1) Thunder Basin station (ID = 817 ) in Washington, $48^{\circ} 31^{\prime} \mathrm{N}, 120^{\circ} 59^{\prime} \mathrm{W}$, with an altitude of $1300 \mathrm{~m}$ a.s.l.; (S2) Brooklyn Lake station in Wyoming (ID = 367 ), $41^{\circ} 22^{\prime} \mathrm{N}, 106^{\circ} 14^{\prime} \mathrm{W}$, with an altitude of $3100 \mathrm{~m}$ a.s.l.; and (S3) Middle Fork Camp station $(\mathrm{ID}=1014)$ in Colorado, $39^{\circ} 36^{\prime} \mathrm{N}, 106^{\circ} 31^{\prime} \mathrm{W}$, with an altitude of $2700 \mathrm{~m}$ a.s.l. In these locations, the precipitation regime is characterized by a winter maximum and a summer minimum with a maximum in snow accumulation during spring. Hourly data of air temperature $T_{\mathrm{A}}$, accumulated precipitation, $h$ and $\mathrm{SWE}$ are available. We have selected data covering the period 1 October 2007-30 September 2011 at S1, 1 October 200630 September 2011 at S2, and 1 October 2001-30 September 2007 for S3 (see http://www.wcc.nrcs.usda.gov/snow/). As for S3, the Water Year (WY) 2005 has been eliminated because of the presence of great noise in the data. We selected these intervals of observation because these years do not suffer technical problems like (1) presence of periods when data are available but only at a coarser resolution, or (2) significant percentage of lacking data. As for S3, some problems occurred in the data series of WY 2002, as confirmed by contacting SNOTEL staff. The interpretation of this interval of data is quite problematic since Colorado experienced a spatially irregular drought during the Water Year 2002 (Pielke et al., 2005). Nevertheless, this site is interesting since it presents hourly data of the variables of interest both in 2002 and 2003, years in which data of liquid water content $(\theta)$ have been collected in the surroundings within the NASA Cold Land Processes Experiment (CLPX 2002/2003), (Elder et al., 2008). These data can allow for validating our results. Therefore, we opted for also considering Water Year 2002 because of the difficulty in finding data at the hourly resolution for that period in other stations close to the CLPX.

In the considered periods, the mean winter temperature is equal to $0.17^{\circ} \mathrm{C}$ at $\mathrm{S} 1,-3.34^{\circ} \mathrm{C}$ at $\mathrm{S} 2$, and $-3.8^{\circ} \mathrm{C}$ at S3, while the maximum snow depth and SWE observed are, re- spectively, $2.72 \mathrm{~m}$ and $970 \mathrm{~mm}$ at $\mathrm{S} 1,2.9 \mathrm{~m}$ and $1087 \mathrm{~mm}$ at $\mathrm{S} 2$, and $1.65 \mathrm{~m}$ and $1170 \mathrm{~mm}$ at S3.

\subsection{Data editing}

In the model (Eqs. 3, 4, and 9), inputs of $T_{\mathrm{A}}$ and $P$ are used. Air temperature is used to infer snow temperature, while $P$ is edited to obtain mass input data series.

Data underwent a process of editing to remove any missing, or wrong, data which could affect the simulation. As for air temperature, any missing data have been removed, replacing them with the value registered at the previous hour. Snow depth data have been also filtered: (i) negative values of $h$ were eliminated, (ii) absolute hourly variations of $h$ greater than $60 \mathrm{~cm}$ were removed, (iii) positive (negative) increments of $h$ followed by negative (positive) values of equal entity were considered erroneous and removed, (iv) any snow depth increment between June and October (not included) has been considered erroneous and removed, and (v) a temperature filter has been applied to remove flutter phenomena. This filtering operation is intended to remove the frequent little instrumental oscillations of snow depth data (at the hourly scale) caused by quick air temperature variations. As a consequence, the filter bases on the hypothesis that temperature fluctuations and snow depth oscillations are related. Any snow depth variation which is contemporaneous to a strong temperature excursion is therefore eliminated. The filtering operation has led to discharge $10 \%$ of data at S1, $7 \%$ at $\mathrm{S} 2$, and $7 \%$ at $\mathrm{S} 3$. As for total precipitation, any negative value and any negative variation has been eliminated, while any negative value of SWE has been replaced by the value registered at the previous hour. Precipitation data input are obtained from the time series of cumulative precipitation, measured in mm of water equivalent, for rain $(p)$ and from the time series of snow depth for snow $(s)$. As for solid events, we have assumed that each hourly positive difference in snow depth data corresponds to a solid event. As for rain, daily increments of total precipitation have been computed and compared with the total daily inputs (in $\mathrm{mm}$ of water equivalent) of solid precipitation. Any positive difference between the two data has been considered as rain and inserted in the model at the end of the day. Here we have considered the precipitation data at the daily time scale as a control volume of the precipitation inputs (solid and liquid) calculated from the hourly time scale data, thus avoiding the presence of false events caused by sensor oscillations due to temperature variations. However, since solid and total precipitations data are derived from two different data series, incongruities can still occur even at the daily scale. As a typical case, total solid precipitation increments could be greater than the corresponding total precipitation increments. To guarantee that the total mass input in the system is equal to that measured by the cumulative precipitation curve, we assumed that rain can occur only if the modeled cumulative precipitation at one day is equal to the measured one, or lower. In this condition, 
the correct reconstruction of rain events could be slightly distorted, but mass input is imposed to be consistent with the measured one. We found a rain/total precipitation ratio of $40 \%$ for S1, of 3\% for S2 and of 30\% for S3 during the year of calibration. Figure $2(3,4)$ reports for S1 $(S 2, S 3)$ two years of daily average of air temperature data in panel (a), and precipitation data in panel (b), in terms of cumulative total precipitation, as measured by the rain gauge in black, cumulative modeled solid precipitation in red and cumulative modeled liquid precipitation in blue. As for panel (a), data have been reported as daily means because of visualization reasons.

\subsection{Model calibration}

Model parameters $(a, b, c)$ are calibrated using the least square method on the first year of data at S1 and S2 (i.e. 2007-2008 for S1, and 2006-2007 for S2), and on the last year of data at S3 (i.e. 2006-2007). The other years (i.e. 3 for $\mathrm{S} 1,4$ for $\mathrm{S} 2$, and 4 for $\mathrm{S} 3$ ) are considered during the validation phase. In particular, snow depth data are used to calibrate $a$ and $b$, while snow density data are used to calibrate $c$. We found the following estimates $a=0.00011\left(\mathrm{~m} \mathrm{~h}^{-1}\right), b=$ $0.00043\left(\mathrm{~m} \mathrm{~h}^{-1}{ }^{\circ} \mathrm{C}^{-1}\right)$, and $c=0.17\left(\mathrm{~m}^{-1} \mathrm{~h}^{-1} \mathrm{~d}^{-1}\right)$ for $\mathrm{S} 1$; $a=0.0001\left(\mathrm{~m} \mathrm{~h}^{-1}\right), b=0.00052\left(\mathrm{~m} \mathrm{~h}^{-1}{ }^{\circ} \mathrm{C}^{-1}\right)$, and $c=1$ $\left(\mathrm{m}^{-1} \mathrm{~h}^{-1} \mathrm{~d}^{-1}\right)$ for $\mathrm{S} 2$; and $a=0.0001\left(\mathrm{~m} \mathrm{~h}^{-1}\right), b=0.00026$ $\left(\mathrm{m} \mathrm{h}^{-1}{ }^{\circ} \mathrm{C}^{-1}\right)$, and $c=1\left(\mathrm{~m}^{-1} \mathrm{~h}^{-1} \mathrm{~d}^{-1}\right)$ for S3. Estimates of $a$ and $b$ are abundant in the literature (WMO, 1965; Braithwaite, 1995; DeWalle and Rango, 2008), while it is not so for values of $c$. Generally, $a$ and $b$ are expressed respectively in $\left(\mathrm{m} \mathrm{d}^{-1}\right)$ and $\left(\mathrm{m} \mathrm{d}^{-1}{ }^{\circ} \mathrm{C}^{-1}\right)$, and their conversion to hourly time scale can be done considering $12 \mathrm{~h}$ as the effective day time. For snowpack, DeWalle and Rango (2008) gave for $b$ the range 0.0002-0004 $\left(\mathrm{m} \mathrm{h}^{-1}{ }^{\circ} \mathrm{C}^{-1}\right)$, while WMO (1965) the interval $0.000083-0.00058\left(\mathrm{~m} \mathrm{~h}^{-1}{ }^{\circ} \mathrm{C}^{-1}\right)$. For glaciers, Braithwaite (1995) estimated $a=0.00025\left(\mathrm{~m} \mathrm{~h}^{-1}\right), b=$ $0.00067\left(\mathrm{~m} \mathrm{~h}^{-1}{ }^{\circ} \mathrm{C}^{-1}\right)$. Our estimates are very close to the ones given in the literature for snowpacks, and smaller than the estimates provided for glaciers, as expected. An estimate of $c$ is found in Nomura (1994), who provided a value of $1 / 6$.

\subsection{Results}

Figures 2, 3 and 4 show the comparison between data and model for S1, S2 and S3, relative to the year of calibration, and one year of validation. In particular, panel (c) reports $h$, panel (d) $\rho$, and panel (e) SWE. For sake of clarity we have reported also $h_{\mathrm{W}}$ in panel (c), and $\rho_{\mathrm{D}}$ in panel (d). We have calculated the Nash-Sutcliffe model efficiency coefficient, $R^{2}$, for each year, and for each of the three variables: $h$, SWE, and $\rho$. For the year of calibration we found that, for $S 1$, the Nash-Sutcliffe coefficient for the snow depth is equal to $R_{h}^{2}=0.95$, for SWE $R_{\mathrm{SWE}}^{2}=0.98$, and for $\rho R_{\rho}^{2}=0.88$, while for $S 2 R_{h}^{2}=0.91, R_{\mathrm{SWE}}^{2}=0.93$, and $R_{\rho}^{2}=0.97$, and for $S 3 R_{h}^{2}=0.87, R_{\mathrm{SWE}}^{2}=0.85$, and $R_{\rho}^{2}=0.73$. For the
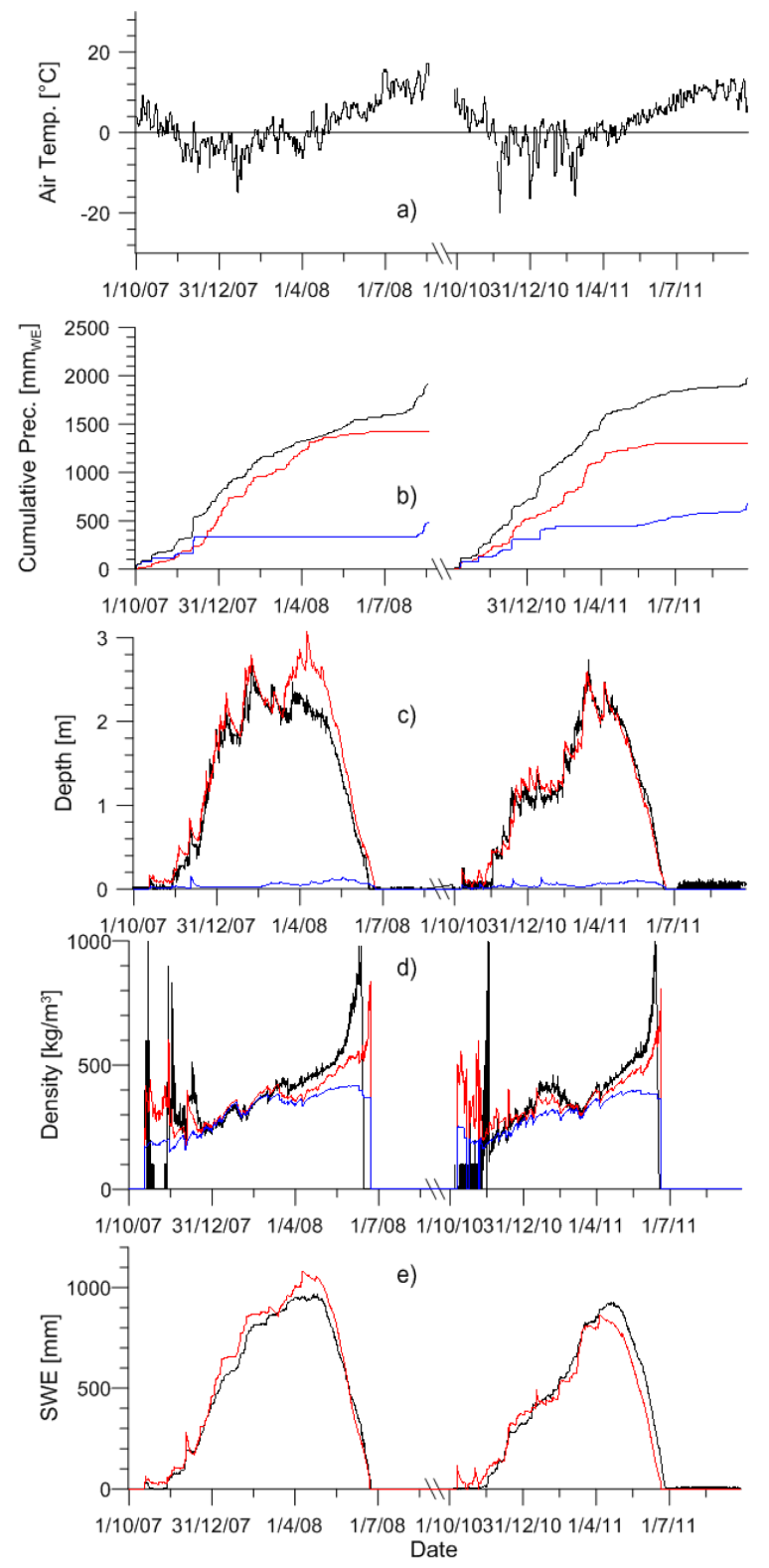

Fig. 2. Meteorological forcings, and dynamics of depth, density and SWE for S1 and two hydrologic years: 2007-2008 (calibration) and 2010-2011 (validation). (a) Air temperature, (b) cumulative precipitation, total observed in black, liquid modeled in blue and solid modeled in red, (c) depth $h$ in red modeled and in black observed, and $h_{\mathrm{W}}$ in blue, (d) density $\rho$ in red modeled and in black observed and $\rho_{\mathrm{D}}$ in blue, and (e) SWE in red modeled and in black observed.

years of validation, we have calculated the mean value of the Nash-Sutcliffe coefficient: $\bar{R}_{h}^{2}=0.89, \bar{R}_{\text {SWE }}^{2}=0.92$, and $\bar{R}_{\rho}^{2}=0.82$ for $\mathrm{S} 1 ; \bar{R}_{h}^{2}=0.84, \bar{R}_{\mathrm{SWE}}^{2}=0.93$, and $\bar{R}_{\rho}^{2}=0.97$ for S2; and $\bar{R}_{h}^{2}=0.85, \bar{R}_{\mathrm{SWE}}^{2}=0.73$, and $\bar{R}_{\rho}^{2}=0.80$ for S3. Note that these values of the Nash-Sutcliffe coefficient are obtained keeping constant parameter values along all the simulation period. 

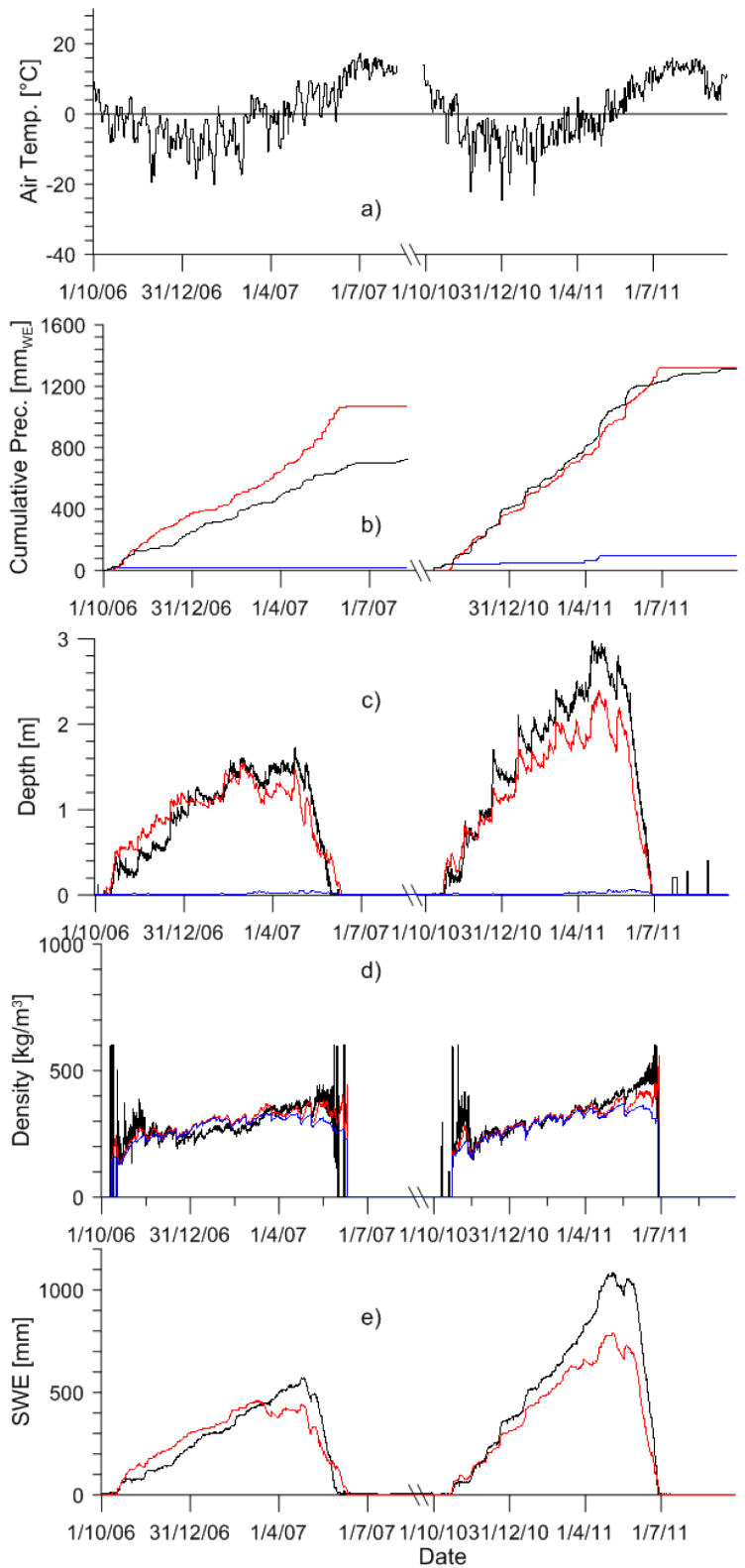

Fig. 3. Meteorological forcings, and dynamics of depth, density and SWE for S2 and two hydrologic years: 2006-2007 (calibration) and 2010-2011 (validation). (a) Air temperature, (b) cumulative precipitation, total observed in black, liquid modeled in blue and solid modeled in red, (c) depth $h$ in red modeled and in black observed, and $h_{\mathrm{W}}$ in blue, (d) density $\rho$ in red modeled and in black observed and $\rho_{\mathrm{D}}$ in blue, and (e) SWE in red modeled and in black observed.

\section{Discussion}

\subsection{Model performances}

The model presents good performances in both the calibration and in the validation phase in all the three sites. As for $\mathrm{S} 1$, it is interesting to note that model performances in calibration and validation phases are quite equivalent, although
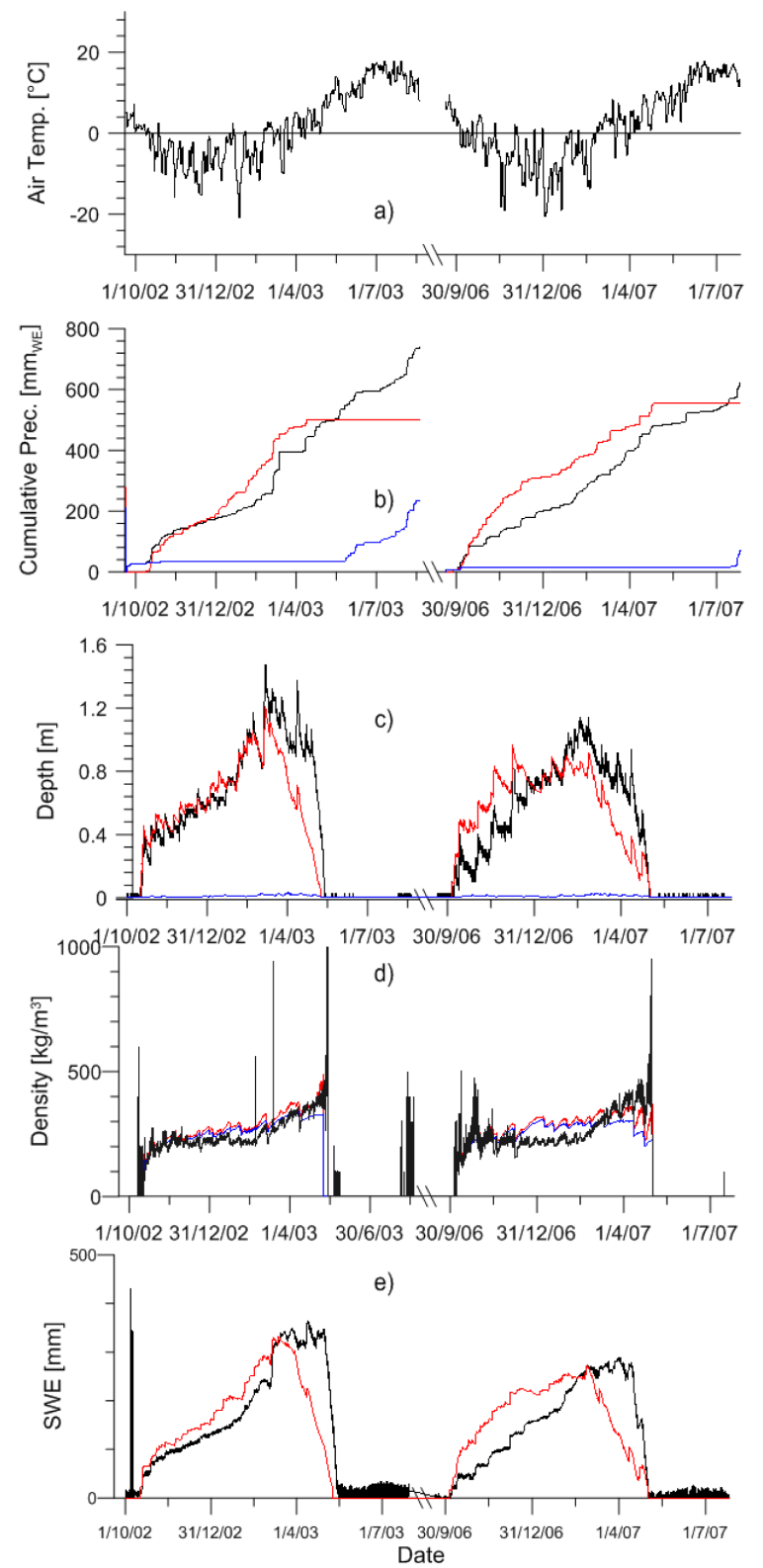

Fig. 4. Meteorological forcings, and dynamics of depth, density and SWE for S and two hydrologic years: 2002-2003 (validation) and 2006-2007 (calibration). (a) Air temperature, (b) cumulative precipitation, total observed in black, liquid modeled in blue and solid modeled in red, (c) depth $h$ in red modeled and in black observed, and $h_{\mathrm{W}}$ in blue, (d) density $\rho$ in red modeled and in black observed and $\rho_{\mathrm{D}}$ in blue, and (e) SWE in red modelled and in black observed.

a slight reduction in the average of the Nash-Sutcliffe coefficient can be observed in the validation period.

For S2, we found that the performances in the validation period are similar to the ones in the year of calibration, as for SWE and snow density, while an evident reduction in the average value of the Nash-Sutcliffe coefficient for snow depth is noticeable. This can be explained referring to the fact that 

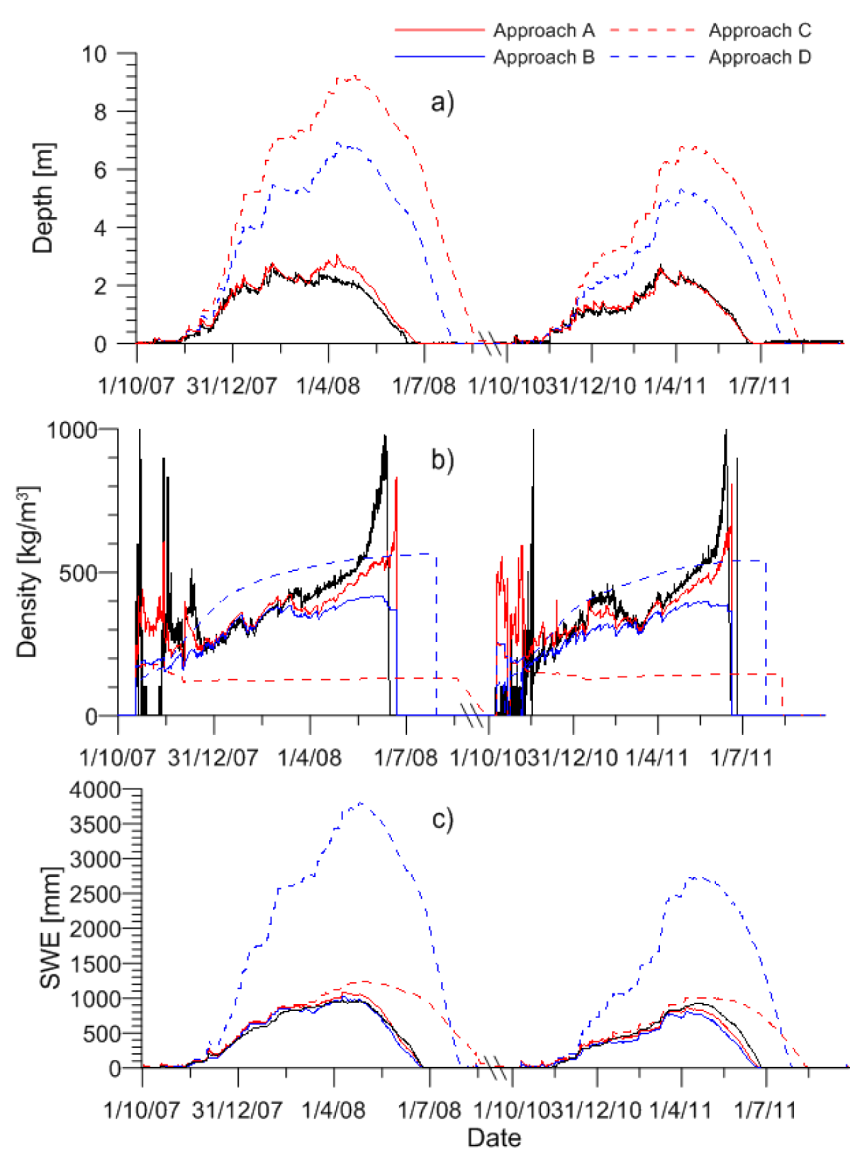

Fig. 5. Comparison between measured data (black line) and four different modeling approaches (A-D), at S1, in terms of (a) snow depth, (b) snow density, and (c) SWE. In red the simulations using the model developed in this contribute (approach A) are reported, in blue the simulations of a dry snowpack model as described by Ohara and Kavvas (2006) (approach B), in red-dashed line the results of a not-compactive snowpack model like that reported by Perona et al. (2007) (approach C), and in blue-dashed line the results of an only-compactive snowpack, for which no effect on snow density is accounted due to new snow events (approach D). In panel (a), simulations of approaches A and B coincide.

snow depth is the state variable which suffers the effects of data editing more than the others.

For S3, a backward validation in the period 2001-2006 is performed to compare model predictions and the available measurements of $\theta$. Model performances are in this case a bit worse than the ones at S1 and S2, especially for SWE and density.

It is evident how problematic is the data editing, and how little fluctuations can affect the correct simulation of the state variables. However, $R^{2}$ values encourage the use of SNOTEL hourly data.

From panel (d) we can appreciate the differences between $\rho$ and $\rho_{\mathrm{D}}$. For S2, located at $3100 \mathrm{~m}$ a.s.l., $\rho$ and $\rho_{\mathrm{D}}$ curves are very close, except for the last part of the melting season, indicating that $\rho_{\mathrm{D}}$ can give a good approximation of $\rho$ during the accumulation and in the first part of the melting season. This is also supported by a small value of the average liquid water content (over the year of calibration), equal to $2 \%$, and by the fact that the condition $\theta<n$ is verified in $99 \%$ of the year. S3 dynamics are very similar to those at S2. The average value of the liquid water content is $2 \%$ and the condition $\theta<n$ is verified in $99 \%$ of the year. On the contrary, for S1, located at a lower altitude, $1300 \mathrm{~m}$ a.s.l., $\rho$ and $\rho_{\mathrm{D}}$ curves are in general different from one to the other, and in this case $\rho_{\mathrm{D}}$ cannot be considered an approximation of $\rho$. In this case the average value of the liquid water content is $4 \%$ and the condition $\theta<n$ is verified in $73 \%$ of the year.

The results show how important the liquid content is for snowpack global density predictions, together with a correct modeling of snow compaction and new events effect. To support this statement, in Fig. 5 we provide a comparison between measured data at S1 and four different modeling approaches of snowpack dynamics, in terms of snow depth (upper panel), density (central panel), and SWE (lower panel). In red we report the model developed in this contribution (approach A), in blue the simulations of a dry snowpack model as reported by Ohara and Kavvas (2006) (approach B), in red-dashed a not-compactive approach like that reported in Perona et al. (2007) (approach C), and in blue-dashed an only-compactive snowpack, for which no effect on snow density is accounted due to new snow events (approach D). As evident, the effects of these simplifications are different if we consider either snow depth, snow density, or SWE. As for snow depth, the results of A and B approaches coincide, since the difference between these two formulations regards the dynamics of the wet phase. On the contrary, a relevant overestimation is visible for approach C. This is quite obvious thinking to the implications of neglecting compaction. As for approach $\mathrm{D}$, it is interesting to show that the simulation results are quite comparable to approach A during the beginning of the accumulation period, while it fails afterwards. In terms of snow density, the importance of accounting for liquid water in snow density dynamics is stressed when observing the difference between approaches $\mathrm{A}$ and $\mathrm{B}$, while approaches $\mathrm{C}$ and $\mathrm{D}$ turn out to be both inadequate in modeling the complexity of snow density dynamics. Also, while approach $\mathrm{C}$ results are unacceptable, approach D succeeds in providing a broad prediction of snow density. This consideration partly explains the acceptable results of approach $D$ in predicting snow depth dynamics. In terms of SWE, approach $\mathrm{D}$ provides a prediction which is comparable to those provided by A and B only at the very beginning of the accumulation period, while it fails afterwards. This is explainable by addressing the previous considerations of snow density. As for approach $\mathrm{C}$, it is evident how considering a constant snow density (as happens after the first days of the season) leads to an overestimation of SWE. Therefore, this comparison demonstrates that the simultaneous simulation of the dry and wet phases, together with modeling of compaction and 

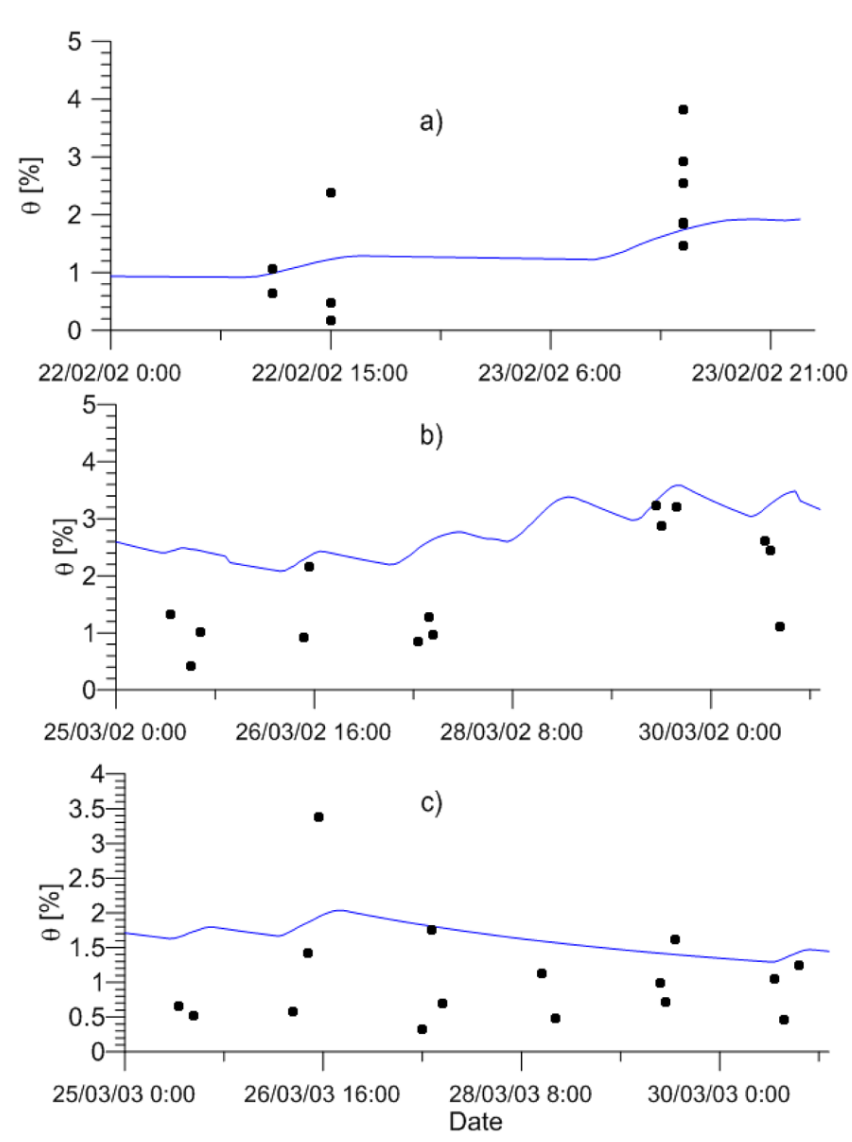

Fig. 6. Comparison between simulated $\theta$ at S3 during three simulation periods in 2002 and 2003 (blue line) and manually measured values of $\theta$ at LSOS site, NASA CLPX field experiment (black dots).

new events effect, is necessary to correctly predict mass, density and depth snow dynamics.

\subsection{Liquid water content validation}

To validate our results, liquid water content $(\theta)$ measurements are needed. According to Techel and Pielmeier (2011), no reliable and automatic procedure of measurement of snow wetness alternative to the manual one is available, so that it is difficult to find hourly data of $\theta$, which could in turn lead us to calibrate and validate wet dynamics on real data. In fact, SNOTEL network does not provide automatic measures of $\theta$ to the final user. Therefore, as a first attempt, we consider here some manual data of snow wetness collected in Colorado within the NASA Cold Land Processes Experiment. We used $\theta$ data collected at the Local Scale Observation Site (LSOS), $39^{\circ} 57^{\prime} \mathrm{N}, 105^{\circ} 54^{\prime} \mathrm{W}$, during February 2002, March 2002 and March 2003. These periods present an overlap with data at $\mathrm{S} 3$, which is $50 \mathrm{~km}$ distant from LSOS site and at a similar elevation (roughly $2700 \mathrm{~m}$ ). The site is characterized by a flat topography, composed by a patchy pine forest and a small clearing. The total area is roughly equal to $8000 \mathrm{~m}^{2}$. Data of snow wetness are available at the http://nsidc.org/data/clpx/. Tha data have been collected in different snow pits with a Denoth meter (Denoth, 1994). Pits have been excavated both in the pine forest and in the clearing. Rough data have been edited by eliminating any negative value, and averaging point values at the same snow pit, but at different depths, to obtain a value which can be compared with the $\theta$ values calculated using Eqs. (3), (4), and (9). As a consequence, each dot in Fig. 6 indicates a different snow pit, with an average value of $\theta$. At a first glance, it is visible how data and modeled values of $\theta$ are always of the same order of magnitude. The maximum absolute difference is equal to roughly $2.5 \%$. The differences between experimental data and the model results can be firstly explained by considering that measurements refer to different snow pits, which are characterized by different covering conditions, and that S3 and LSOS site are rather distant. Secondly, these differences could be also caused by refreezing, which is not considered in this formulation, and which would decrease the modeled value of $\theta$ during the night hours. This consideration explains why model predictions of $\theta$ usually overestimate measured data in panels (b) and (c). As for February 2002, panel (a), the considered period of observation is too limited to infer a solid conclusion. As stated by Elder et al. (2008), data refer to a snowpack which can be considered as dry in February and at the beginning of the wet period in March. Therefore, it is possible to state that the model ensures good predictions of $\theta$ in these conditions. This consideration is reinforced by the fact that just a part of the real interval of variation of $\theta$ is reported in Fig. 6. This comparison represents just a preliminary attempt to validate our results, since time-continuous data is strongly needed, especially for the last part of the melting season. Its development is a mandatory element for the future of our work.

\section{Conclusions}

We have presented a one-dimensional model for the dynamics of a snowpack, with particular attention to bulk snow density dynamics in dry and wet conditions. The snowpack is represented as a two-constituent mixture: a dry part including ice structure, and air, and a wet part constituted by liquid water. The model includes mass balance equations of dry and wet constituents, momentum balance and rheological equations for the dry part, and a simplified energetic description of the snowpack. The model results in a system of three differential equations in the variables, depth and density of the dry part and depth of liquid water, forced by precipitation and air temperature data input, with a parsimonious parametrization; only three parameters to be calibrated. The model has been tested against hourly data registered in three SNOTEL stations: Thunder Basin station for 2008-2011 period, Brooklyn Lake station in the period 2007-2011, and Middle Fork Camp in the period 2002-2007. The model 
shows a good agreement with data of snow density, snow depth and SWE, not only in calibration but also in validation phase, with mean values of the Nash-Sutcliffe coefficient in the range $(0.73,0.97)$. Improvement of performances could be obtained by including within the model refreezing, sublimation and evaporation terms. The model seems suitable to predict the snowpack dynamics starting from hydroclimatic inputs. The general good ability of the simulations in reproducing measured snow density confirms our preference for an integral one-dimensional model, which avoids the local incongruities in snow density modeling during the snowmelt season, as pointed out by Koivusalo et al. (2001). This analysis will be extended to the other stations of SNOTEL network in order to make other tests on the model performances and to investigate the variability of the calibration parameters, especially for the site-specific parameter $c$. In addition, a more extended validation of the liquid water content dynamics is necessary and will be the object of a future study.

Acknowledgements. We would like to express our sincere gratitude to all the SNOTEL technicians, whose contribute has been essential for this work. In particular, we would like to thank Julie Koeberle, Magdalene Skordahl, Richard McClure, Melissa Webb, Jim Marron, Scott Pattee, Randall Julander, Dino De Simone, Mike Gillespie, Brian Domonkos, Austin Beard, Kenneth VonBuettner, Michael Bricco, Scott Oviatt, Daniel Fisher, Jeff Anderson and Phil Morrisey. We would also like to thank the National Snow and Ice Data Center for their willingness and assistance in sharing CLPX data. We thank the editor Martin Schneebeli, Richard Essery, and two anonymous reviewers for their helpful comments.

Edited by: M. Schneebeli

\section{References}

Anderson, E. A.: A Point Energy and Mass Balance Model of a Snow Cover, NOAA Technical Report NWS, 19, 150 pp., 1976.

Bales, R. C., Molotch, N. P., Painter, T. H., Dettinger, M. D., Rice, R., and Dozier, J.: Mountain hydrology of the western United States, Water Resour. Res., 42, W08432, doi:10.1029/2005WR004387, 2006.

Barnett, T. P., Adam, J. C., and Lettenmaier, D. P.: Potential impacts of a warming climate on water availability in snow-dominated regions, Nature, 438, 303-309, 2005.

Bartelt, P. and Lehning, M.: A physical SNOWPACK model for the Swiss avalanche warning - Part I: Numerical Model, Cold Reg. Sci. Technol., 35, 123-145, 2002.

Bavera, D. and De Michele, C.: Snow Water Equivalent estimation in Mallero basin using snow gauge data and MODIS images and fieldwork validation, Hydrol. Proc. 23, 1961-1972, 2009.

Bavera, D., De Michele, C., Pepe, M., and Rampini, A.:, Melted snow volume control in the snowmelt runoff model using a snow water equivalent statistically based model, Hydrol. Proc., 26, 3405-3415, doi:10.1002/hyp.8376, 2012.
Braithwaite, R. J.: Positive degree-day factors for ablation on the Greenland ice sheet studied by energy-balance modelling, J. Glaciol., 41, 153-159, 1995.

Colbeck, S. C.: Water flow through snow overlying an impermeable boundary, Water Resour. Res., 10, 119-123, 1974.

Denoth, A.: An electronic device for long-term snow wetness recording, Ann. Glaciol., 19, 104-106, 1994.

DeWalle, D. R. and Rango, A.: Principles of snow hydrology, Cambridge University Press, New York, 2008.

Dietz, A. J., Kuenzer, C., Gessner, U., and Dech, S.: Remote sensing of snow - a review of available methods, Int. J. Remote Sens., 33, 4094-4134, 2011.

Elder, K., Cline, D., Liston, G. E., and Armstrong, R.: NASA Cold Land Processes Experiment (CLPX 2002/03): Field measurements of snowpack properties and soil moisture, J. Hydrometeorol., 10, 320-329, 2008.

Essery, R., Martin, E., Douville, H., Fernandez, A., and Brun, E.: A comparison of four snow models using observations from an alpine site, Clim. Dynam., 15, 583-593, 1999.

Fierz, D. M., Armstrong, C., Durand, R. L., Etchevers, R. L., Greene, P., McClung, E., Nishimura, K., Satyawali, P. K., and Sokratov, S. A.: The International Classification for Seasonal Snow on the Ground, IHP-VII Technical Documents in Hydrology N83, Contribution N1, UNESCO-IHP, Paris, 2009.

Gerdel, R. W.: The transmission of water through snow, Trans. Am. Geophys. Union, 35, 475-485, 1954.

Hock, R.: A distribuited temperature-index ice and snowmelt model including potential direct solar radiation, J. Glaciol., 45, 101111, 1999.

Hock, R.: Temperature index melt modelling in mountain areas, J. Hydrol., 282, 104-115, 2003.

Izumi, K. and Akitaya, E.: Hardness of wet snow, Ann. Glaciol., 6, 267-268, 1985.

Kelleners, T. J., Chandler, D. G., McNamara, J. P., Gribb, M. M., and Seyfried, M. S.: Modeling the water and energy balance of vegetated areas with snow accumulation, Vadose Zone J., 8, 1013-1030, 2009.

Kerkez, B., Glaser, S. D., Dracup, J. A., and Bales, R. C.: Hybrid system model of seasonal snowpack water balance, Hybrid Systems: computation and control, 13th International Conference, Stockholm, Sweden, Proceedings of the ACM, 2010.

Koivusalo H., Heikinheimo, M., and Karvonen, T.: Test of a simple two-layer parameterisation to simulate the energy balance and temperature of a snowpack, Theor. Appl. Climatol., 70, 65-79, 2001.

Kojima, K.: Densification of seasonal snow cover, Proc. Internat. Conf. Physics Snow Ice, 1, 929-952, 1967.

Kondo ,J. and Yamazaki, T.: A prediction model for snowmelt, snow surface temperature and freezing depth using a heat balance method, J. Appl. Meteorol., 29, 375-384, 1990.

Kongoli, C. E. and Bland, W. L.: Long-term snow depth simulations using a modified atmosphere-land exchange model, Agr. Forest Meteorol., 104, 273-287, 2000.

Jansson, P. E. and Karlberg, L.: Coupled heat and mass transfer model for soil-plant-atmosphere systems, R. Inst. Technol., Dep. Civil Environ. Eng., Stockholm, Sweden, 2004.

Jonas T., Marty, C., and Magnusson, J.: Estimating the snow water equivalent from snow depth measurements in the Swiss Alps, J. Hydrol., 378, 161-167, 2009. 
Jordan, R.: A one-dimensional temperature model for a snow cover: Technical documentation for SNTHERM.89, Spec. Rep. 91-16, US Army Corps of Eng., Cold Regions Res. Eng. Lab., Hanover, 1991.

Lehning, M., Bartelt, P., Brown, B., and Fierz, C.: A physical SNOWPACK model for the Swiss avalanche warning Part III: meteorological forcing, thin layer formation and evaluation, Cold Reg. Sci. Technol., 35, 169-184, 2002.

Marks, D., Kimball, J., Tingey, D., and Link, T.: The sensitivity of snowmelt processes to climate conditions and forest cover during rain-on-snow: A case study of the 1996 Pacific Northwest flood, Hydrol. Proc., 12, 1569-1587, 1998.

Marsh, P. and Woo, M. K.: Wetting front advance and freezing of meltwater within a snow cover: 1 . Observations in the Canadian Arctic, Water Resour. Res., 20, 1853-1864, 2004.

Marshall, H. P., Conway, H., and Rasmussen, L. A.: Snow densification during rain, Cold Reg. Sci. Technol., 30, 35-41, 1999.

Mellor, M.: A review of basic snow mechanics. Snow Mechanics Symposium (Proceedings of the Grindelwald Symposium, April 1974) IAHS Publication, 114, 251-291, 1975.

Meløysund, V., Leira, B., Høiseth, K., and Lisø, K. R.: Review: Predicting snow density using meteorological data, Meteorol. Appl., 14, 413-423, 2007.

Mizukami, N. and Perica, S.: Spatiotemporal characteristics of snowpack density in the mountainous regions of the western United States, J. Hydrometeorol., 9, 1416-1426, 2008.

Nomura, M.: Studies on the delay mechanism of runoff to snowmelt Contributions from the Institute of Low Temperature Science, Hokkaido University, 39, 1-49, 1994.

Ohara, N. and Kavvas, M. L.: Field observations and numerical model experiments for the snowmelt process at a field site, Adv. Water Resour., 29, 194-211, 2006.

Ohmura, A.: Physical basis for the temperature-based melt-index method, J. Appl. Meteorol., 40, 753-761, 2001.

Perona, P., Porporato, A., and Ridolfi, L.: A stochastic process for the interannual snow storage and melting dynamics, J. Geophysical Res., 112, D08107, doi:10.1029/2006JD007798, 2007.

Pielke, R. A., Doesken, N., Bliss, O., Green, T., Chaffin, C., Salas, J. D., Woodhouse, C. A., Lukas, J. J., and Wolter, K.: Drought 2002 in Colorado: An unprecedented drought or a routine drought?, Pure Geophys., 162, 1455-1479, 2005.
Pierce, D. W., Barnett, T. P., Hidalgo, H. G., Das, T., Bonfils, C., Santer, B. D., Bala, G., Dettinger, M. D., Cayan, D. R., Mirin, A., Wood, A. W., and Nozawa, T.: Attribution of Declining Western US Snowpack to Human Effects, J. Clim., 21, 6425-6444, 2008.

Rutter, N., Cline, D., and Li, L.: Evaluation of the NOHRSC Snow Model (NSM) in a One-Dimensional Mode, J. Hydrometeorol., 9, 695-711, 2008.

Schneebeli, M.: Development and stability of preferential flow paths in a layered snowpack, in: Biogeochemistry of seasonally snow-covered catchments, Boulder, July, Vol. 228, edited by: Tonnessen, K. A., Williams, M. W., and Tranter, M., Int. Assoc. Hydrol. Sci., Wallingford, 89-95, 1995.

Serreze, M. C., Clark, M. P., Armstrong, R. L., McGinnis, D. A., and Pulwarty, R. S.: Characteristics of the western United States snowpack from snowpack telemetry (SNOTEL) data, Water Resour. Res., 35, 2145-2160, 1999.

Singh, V. P.: Kinematic wave modelling in water resources: a historical perspective, Hydrol. Proc., 15, 671-706, 2001.

Tarboton, D. G. and Luce, C. H.: Utah energy balance snow accumulation and melt model (UEB): Computer model technical description and users guide, Utah Water Res. Lab., Logan, 1996.

Techel, F. and Pielmeier, C.: Point observations of liquid water content in wet snow - investigating methodical, spatial and temporal aspects, The Cryosphere, 5, 405-418, doi:10.5194/tc-5-4052011, 2011.

van den Broeke, M., Bus, C., Ettema, J., and Smeets, P.: Temperature thresholds for degree-day modelling of Greenland ice sheet melt rates, Geophys. Res. Lett., 37, L18501, doi:10.1029/2010GL044123, 2010.

Vionnet, V., Brum, E., Morin, S., Boone, A., Faroux, S., Le Moigne, P., Martin, E., and Willemet, J.-M.: The detailed snowpack scheme Crocus and its implementation in SURFEX v7.2, Geosci. Model Develop., 5, 773-791, 2012.

Waldner, P. A., Schneebeli, M., Schultze-Zimmerman, U., and Fluhler, H.: Effect of snow structure on water flow and solute transport, Hydrol. Proc., 18, 1271-1290, 2004.

WMO: Guide to hydrometeorological pratices, 168, TP82, 281 pp., 1995.

Zhang, T.: Influence of the seasonal snow cover on the ground thermal regime: An overview, Rev. Geophys., 43, 23 pp., 2005.

Zhang, Y., Wang, S., Barr, A. G., and Black ,T. A.: Impact of snow cover on soil temperature and its simulation in a boreal aspen forest, Cold Reg. Sci. Technol., 52, 355-370, 2008. 